\title{
FIRST RECORDS OF DIROFILARIA REPENS IN WILD CANIDS FROM THE REGION OF CENTRAL BALKAN
}

\author{
Duško ĆIRović ${ }^{1 *}$, Aleksandra PENEZIĆ ${ }^{1}$, Ivan PAVLoviĆ ${ }^{2}$, Zoran KuLIŠIĆ ${ }^{3}$, Nada Ćosić ${ }^{4}$, \\ Jelena BURAZEROVIĆ ${ }^{1}$ and Vladimir MALETIĆ ${ }^{5}$ \\ ${ }^{1}$ Faculty of Biology, University of Belgrade, Studentski trg 16, 11000 Belgrade, Serbia; \\ ${ }^{2}$ Scientific Institute of Veterinary Medicine of Serbia, Belgrade, Serbia; ${ }^{3}$ Faculty of \\ Veterinary Medicine, University of Belgrade, Belgrade, Serbia; ${ }^{4}$ Institute for Biological \\ Research 'Siniša Stanković', University of Belgrade, Belgrade, Serbia; ${ }^{5}$ Faculty of \\ Forestry, Ss. Cyril and Methodius University in Skopje, Skopje, Republic of Macedonia
}

(Received 6 May 2014; accepted 25 June 2014)

\begin{abstract}
Dirofilaria repens causes an emerging zoonotic disease in Europe, particularly in its southern part, the Mediterranean region. Many reports on human dirofilariosis have been published recently, but little is known about the wildlife hosts and reservoirs of this parasite in nature. This paper presents the first records of adult $D$. repens specimens from free-ranging carnivores in Central Balkan countries (Serbia and Macedonia). During the period 2009-2013, a total of 145 regularly shot canids were examined for the presence of $D$. repens adults. In order to investigate their role as hosts and potential wild reservoirs of this zoonosis, 71 wolves (Canis lupus), 48 foxes (Vulpes vulpes) and 26 jackals (Canis aureus) were examined. Under the skin of two wolves (one from Serbia and one from Macedonia) and of a red fox from Serbia $D$. repens adults were found. In all three cases only one parasite was present. Further research on wild canids is needed, particularly on species widening their range (such as jackals) and those living near human settlements (foxes and jackals), which facilitates the transmission of the parasites to dogs and humans.
\end{abstract}

Key words: Dirofilaria repens, wild carnivores, Central Balkan, first records, Serbia, Macedonia

Dirofilaria repens is an endoparasite from the phylum Nematoda and one of six species from the genus Dirofilaria, which is confirmed to cause zoonotic infections (Orihel and Eberhard, 1998). This roundworm parasitises mainly dogs but also other carnivorous animals and humans. The distribution of $D$. repens is exclusive to the Old World. In Europe, it is commonly found in the Mediterranean region and Eastern Europe, but an expansion towards Northern and Central European countries has been observed. Adult worms usually live in the subcuta-

*Corresponding author; E-mail: dcirovic@bio.bg.ac.rs; Phone: 00381 (11) 263-7024; Fax: 00381 (11) 263-8500 
neous tissue of the host, but sometimes they may also be found in the abdominal cavity, in the kidneys, lymph nodes or intestinal wall linings. The vectors are numerous mosquito species of the genera Culex, Aedes and Anopheles (Pampiglione et al., 1995; Cancrini et al., 2006). Mosquitoes ingest microfilariae during a blood meal on an infected host. Inside mosquitoes, microfilariae develop into a second larval stage $\left(\mathrm{L}_{2}\right)$ and then into an infectious third larval stage $\left(\mathrm{L}_{3}\right)(\mathrm{Genchi}$ et al., 2009). In a subsequent blood meal, the female mosquito will infect a new host. Dirofilaria repens reaches its sexual maturity in the host 6 to 9 months after infection (Webber and Hawking, 1955; Manfredi et al., 2007).

Dirofilaria repens also causes a zoonotic disease called human dirofilariosis. Many European countries are considered enzootic for this type of zoonosis. However, recent rapid spreading towards Central and Western Europe has raised concerns related to this disease (Pampiglione et al., 1999, 2001; Svobodova et al., 2006). Also, an increasing number of human infections are reported in Europe (Genchi et al., 2009; Pampiglione et al., 1999, 2001). This rapid spread of D. repens can be explained by the global climate change (Genchi et al., 2009; Otranto et al., 2013), the high number of mosquitoes in urban settings (Valerio et al., 2008) and their generalist feeding behaviour (Romi and Majori, 2008; Valerio et al., 2008).

The natural hosts of $D$. repens are dogs and other carnivores. Besides, some researchers suggest that wild carnivores such as foxes may be significant wild reservoirs for zoonotic filarioids (Magi et al., 2008). With an exception of a few studies on the presence of microfilariae in the blood of domestic dogs (Tasic et al., 2008, 2012; Kočevski et al., 2010) and human dirofilariosis case reports (Stefkov and Gjorgov, 1967; Cvetković et al., 2007; Džamić et al., 2009; Tasić et al., 2011; Jurhar Pavlova et al., 2012), no research has been conducted so far on wild animals, either in Serbia or in the Former Yugoslav Republic of Macedonia. The aim of this study was to present the first data on D. repens in wild canids from the Central Balkan and to help understand the importance of these species as hosts and potential reservoirs of dirofilariosis in nature.

\section{Materials and methods}

The aim of our parasitological studies, conducted in the period 2009-2013 on several canid species (wolf, jackal and fox), was to check the presence of $D$. repens adult specimens. Our study included a total of 145 legally shot animals: wolves (Canis lupus) from Serbia ( 37 males and 24 females) and from Macedonia (6 males and 4 females), red foxes (Vulpes vulpes) from Serbia (24 males and 12 females) and from Macedonia (8 males and 4 females), and golden jackals (Canis aureus) (15 males and 11 females) from Serbia. For all the animals, sex, date of death and location where shot were recorded. For the purpose of pre- 
paring taxidermy mounts, the animal was skinned and the subcutaneous tissue was carefully examined in order to find adult forms of $D$. repens.

In order to be preserved intact, all the parasites were carefully removed from the subcutaneous tissue. Until final determination, worms were preserved in saline and glycerine-alcohol ( $70 \%$ ethyl alcohol and 5\% glycerine). Identification of the parasites was based on morphological characters (Gutierrez, 1984; Pampiglione et al., 1995; Orihel and Eberhard, 1998). Wet preparations for microscopic examination were made with saline, glycerine and chloral-lactophenol. Morphological characters of the parasites such as shape, cuticle features, length, width, caudal and cephalic end, anal and vaginal openings were measured and examined using the optical microscope with $5 \times 10 \times 20$ magnification.

Apart from macroscopic determination, D. repens was also identified on the basis of cross-section of the parasite in the histology slides. The worm was fixed in $10 \%$ neutral formalin, then dehydrated using a series of different concentrations of alcohol as a preparation for histopathological cuts. It was moulded in paraffin moulds and cuts were made with a microtome. The slide was stained with haematoxylin and eosin (Fig. 3)

Most animal carcasses were in bad condition unsuitable for testing the blood for the presence of microfilariae.

\section{Results}

A total of 145 wild canids were examined and only three were infected with $D$. repens: two wolves (one from the northeastern part of Serbia and one from central Macedonia) and one red fox from the northeastern part of Serbia (Fig. 1). A male D. repens adult was found in the subcutaneous tissue (Fig. 2a) of a female wolf (shot on 14 February 2010) from the area surrounding the town of Sveti Nikole (Macedonia) and a female D. repens adult was found in a male wolf (shot on 15 December 2013) from the surroundings of the village Zatonje (Serbia). In both animals one parasite per host was found in the same position, in the bend of the left foreleg. Out of 48 red foxes examined from Serbia and Macedonia only one male was infected. This red fox was shot on 10 February 2013 in the vicinity of the village Vodanj in Serbia (Fig. 1). One female adult worm was subcutaneously implanted on the head, in the occipital region (Fig. 2b). In 16 golden jackals examined from Serbia no infection caused by $D$. repens adults was observed.

The parasites were whitish in colour, their length, tapering at the ends, was in average $(\mathrm{n}=3) 155 \mathrm{~mm}$ and their diameter $0.8 \mathrm{~mm}$. The anterior part of the body was rounded and the tail blunted and mildly bent ventrally. The cuticle has a clearly visible longitudinal and pale transverse pattern. The lip opening was small, lipless, with a rudimentary lip capsule surrounded by four pair of papillae. 


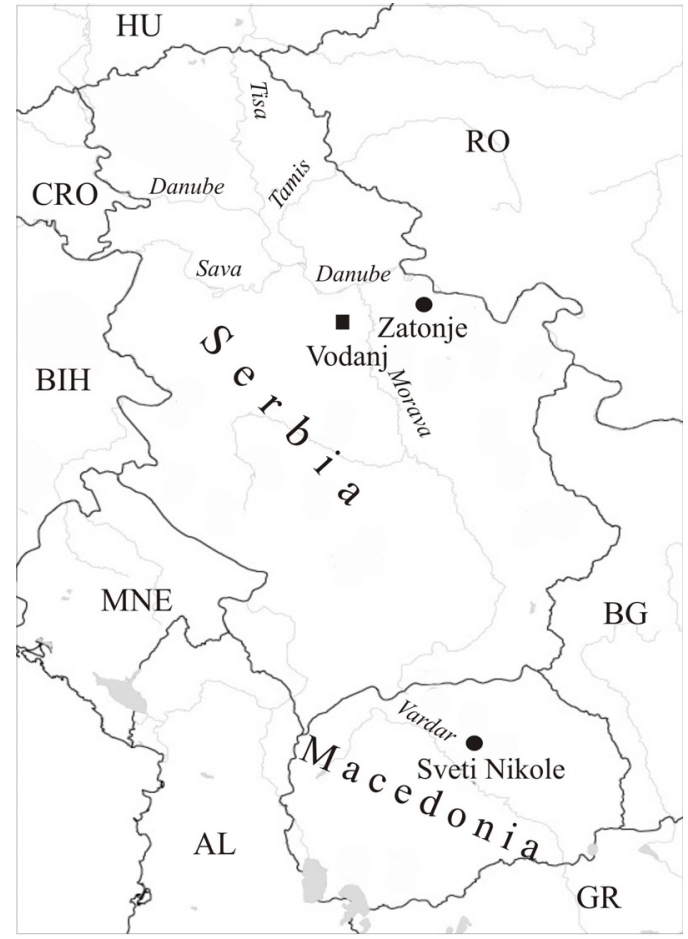

- Infected wolf

- Infected red fox

Fig. 1. Distribution of localities where the animals infected with Dirofilaria repens were collected
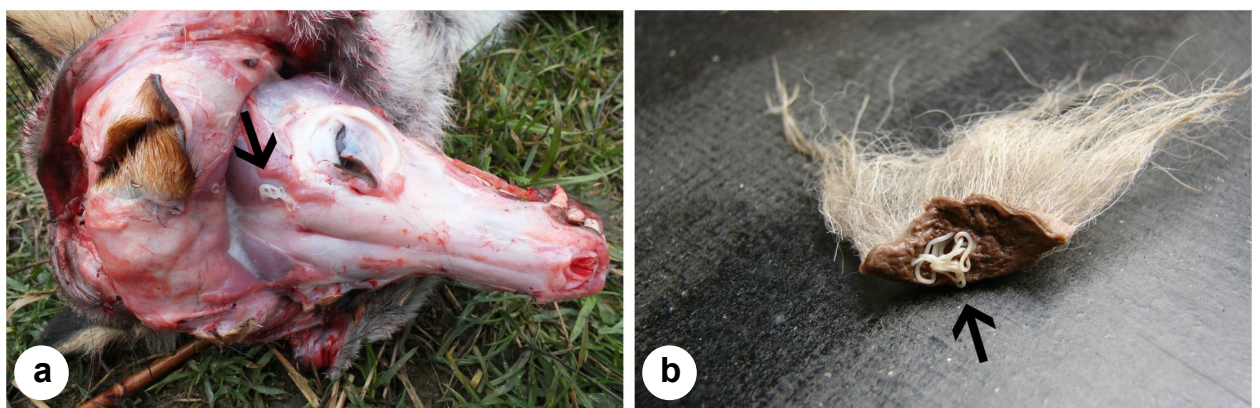

Fig. 2. Subcutaneously located Dirofilaria repens a) in a red fox (Vulpes vulpes) and b) in a wolf (Canis lupus)

The cuticle of worms was thick and multilayered. On the external layer, there were regularly distributed longitudinal ridges. No such ridges were observed at either the anterior or the posterior side of the parasite. The muscle layer 
was well developed and it was in radial position inside the cuticle. The cuticle, the muscle layer, the longitudinal ridges of the external layer, the intestine and the uterus can be seen on the cross-section of the female worm (Fig. 3).

On the outer side of the skin, there was no oedema, redness or any other visible sign of parasite presence in any of the three cases of infection.

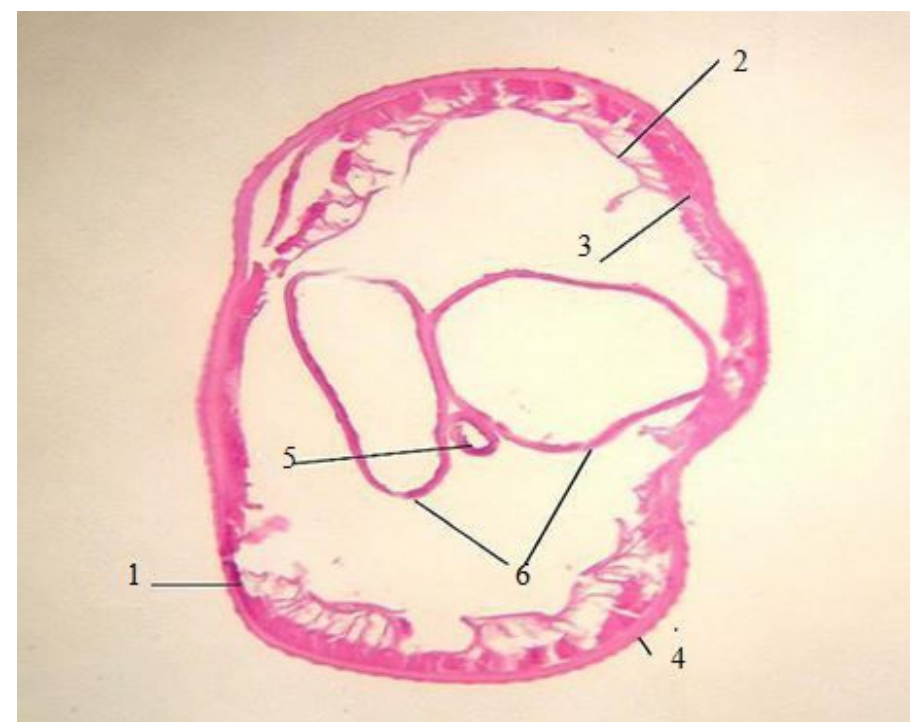

Fig. 3. Cross-section of female D. repens. 1 - cuticle, 2 - muscle layer, 3 - radial muscular layer, 4 - longitudinal ridge of external layer, 5 -intestine, 6 - uterus in pseudocoelom

\section{Discussion}

Serbia is an endemic area for $D$. repens (as well as for D. immitis, see Otranto et al., 2013), due to its climate conditions supporting the development of numerous mosquito species such as those already recognised as vectors of $D$. repens (Anopheles maculipennis and Aedes albopictus). No study in Serbia or in Macedonia has been conducted so far on wild animals. All previous research on animals was based on studies concerning the presence of microfilariae in the blood of owned dogs. A study conducted during 2006 and 2007 showed that microfilariae of $D$. repens were present in $49.2 \%$ of $193 \mathrm{dogs}$ examined in Vojvodina, the northern province of Serbia (Tasić et al., 2008). In another study conducted in 2009 in the northeastern part of the country, D. repens microfilariae were detected in 21 out of $122(17.2 \%)$ pet dogs examined (Tasić et al., 2012). Case studies of human dirofilariosis increased in number during the last decade. According to Džamić et al. (2009), until 2008 a total of 28 cases had been reported of which 19 occurred in the period from 2001 to 2008. The southernmost 
reports on human dirofilariosis are from Vranje and Prizren where the patients had worms in the subconjunctival and periocular tissues (Tasić et al., 2011; Jakšić et al., 2011). A recent study has shown that seroreactivity to D. repens antigens was found in 29 out of 297 people examined (9.8\%) from 7 different areas of Serbia (Tasić-Otašević et al., 2014). The same study points out that the highest seroreactivity is recorded in the northeastern part of the country (Pančevo, 27.1\%) close to sites where $D$. repens was found in wild animals in this study. These findings suggest that this disease is becoming an emergent zoonosis in Serbia.

Data about dirofilariosis in Macedonia are scarce. The only study on animals was conducted on professional dogs of different breeds from the region of Skopje (Kočevski et al., 2010). Out of 39 dogs examined, the presence of $D$. repens microfilariae was recorded in 8 cases, which indicates their relative high prevalence $(20.5 \%)$. Certainly, such a high prevalence is the result of climatic factors favouring the development of mosquitoes serving as transient hosts (Valerio et al., 2008). Moreover, only three cases of human dirofilariosis caused by $D$. repens have been reported so far in Macedonia. The first case of human dirofilariosis was reported in 1967 (Stefkov and Gjorgov, 1967) as subcutaneous nodular dirofilariosis. The second case in Macedonia was described 40 years after the first one by Cvetković et al. (2007). A male patient from the village Trubarevo (near Skopje) had a 13-cm-long D. repens in the subconjunctiva of his left eye. The third report is from 2011 (Jurhar Pavlova et al., 2012), where a 52year-old female patient claimed that something had been moving under her skin for 3 years. Finally, an about 14-cm-long parasite was removed from her nose. Interestingly, that woman is from the village of Gorobinci which is situated in the municipality of Sveti Nikole, the same region where the wolf in which D. repens was found was shot in 2010. For this reason we suggest that more profound research on Dirofilaria occurrence in that region, as well as in the northeastern part of Serbia, should be conducted.

Due to the small number of studies conducted on wild animals regarding D. repens infection, it is difficult to discuss the role of wild carnivores in natural cycles or as reservoirs. The only comprehensive study on wild carnivores from Italy showed that the red fox can be considered a wild reservoir for zoonotic filarioids (Magi et al., 2008). In that study, 23 out of 132 specimens (17.4\%) proved to be positive for microfilariae. Our findings contribute to the knowledge of wild canids acting as hosts and potential reservoirs of dirofilariosis in nature. Further research is needed on foxes and jackals since they often live near human settlements, increasing the chance of the transmission of larvae to dogs and humans. Moreover, jackals are spreading towards Central and Western Europe from the Balkans, and their role as wildlife reservoirs of D. repens infection should be investigated more thoroughly. 


\section{Acknowledgements}

The authors wish to express their gratitude to taxidermists Srđan Vučković and Gradimir Koturović for their assistance with stripping off the skin from animals, and numerous hunters for collecting bodies of animals for this research. This study was supported by the Ministry of Education, Science and Technological Development of the Republic of Serbia (Contract OI 173006). The authors are grateful to the two reviewers and the editor for their useful comments and advices.

\section{References}

Cancrini, G., Magi, M., Gabrielli, S., Arispici, M., Tolari, F., Dell'omodarme, M. and Prati, M. C. (2006): Natural vectors of dirofilariasis in rural and urban areas of the Tuscan region, central Italy. J. Med. Entomol. 43, 574-579.

Cvetković, D., Dokik Trajkovska, E., Pavlova Jurhar, M., Petrovska, M., Panovski, N., Grdanoska, T. and Duma, H. (2007): Diagnosis of dirofilariasis: a case report. Mak. Med. Pregled 61, 71.

Džamić, A. M., Čolović, I. V., Arsić-Arsenijević, V. S., Stepanović, S., Boričić, I., Džamić, Z., Mitrović, S. M., Rašić, D. M., Stefanović, I., Latković, Z. and Kranjčić-Zec, I. F. (2009): Human Dirofilaria repens infection in Serbia. J. Helminthol. 83, 129-137.

Genchi, C., Rinaldi, L., Mortarino, M., Genchi, M. and Cringoli, G. (2009): Climate and Dirofilaria infection in Europe. Vet. Parasitol. 163, 286-292.

Gutierrez, Y. (1984): Diagnostic features of zoonotic filariae in tissue sections. Hum. Pathol. 15, 514-525.

Jakšić, V., Mitić, N., Pavlović, I., Vitošević, Z., Mirković, M., Zorić, L., Stamenković, D., Vukša, D. and Đokić, O. (2011): Discrete eyelid swelling caused by live subconjunctival Dirofilaria repens. Cent. Eur. J. Med. 6, 177-180.

Jurhar Pavlova, M., Cvetković, D., Duma, H., Kochevski, Z., Jankoska, G. and Petrovska, M. (2012): Dirofilariasis in R. Macedonia - an overview of literature data and our experiences. 46th Days of Preventive Medicine, International Congress. Niš, Serbia, 25-28 September 2012. Book of Abstracts. pp. 130-132.

Kočevski, Z., Atanasovska, E., Nikolovski, G. and Stefanovska, J. (2010): Presence of Dirofilaria repens in professional dogs in the region of Skopje diagnosed with the modified Knott technique. Days of Veterinary Medicine. Ohrid, R. Macedonia, 28-30 October 2010. Book of Abstracts. p. 63.

Magi, M., Carderini, P., Gabrielli, S., Dell'Omodarme, M., Macchioni, F., Prati, M. C. and Cancrini, G. (2008): Vulpes vulpes: a possible wild reservoir for zoonotic filarie. Vector-Borne Zoonot. 8, 249-252.

Manfredi, M. T., Di Cerbo, A. and Genchi, M. (2007): Biology of filarial worms parasitizing dogs and cats. In: Genchi, C., Rinaldi, L. and Cringoli, G. (eds) Dirofilaria immitis and D. repens in Dog and Cat and Human infections. Mappe Parassitologiche, Vol. 8. Universita degli Studi di Napoli Federico II, Naples, Italy. pp. 39-47.

Orihel, T. C. and Eberhard, M. L. (1998): Zoonotic filariasis. Clin. Microbiol. Rev. 11, 366-381.

Otranto, D., Dantas-Torres, F., Brianti, E., Traversa, D., Petrić, D., Genchi, C. and Capelli, G. (2013): Vector-borne helminths of dogs and humans in Europe. Parasit. Vectors 6, 16.

Pampiglione, S., Canestri, T. G. and Rivasi, F. (1995): Human dirofilariasis due to Dirofilaria (Nochtiella) repens: a review of world literature. Parassitologia 37, 149-193.

Pampiglione, S., Elek, G., Pálfi, P., Vetési, F. and Varga, I. (1999): Human Dirofilaria repens infection in Hungary: a case in the spermatic cord and a review of the literature. Acta Vet. Hung. 47, 77-83. 
Pampiglione, S., Rivasi, F., Angeli, G., Boldorini, R., Incensati, R. M., Pastormerlo, M., Pavesa, M. and Ramponi, A. (2001): Dirofilariasis due to Dirofilaria repens in Italy, an emergent zoonosis: report of 60 new cases. Histopathology 38, 344-354.

Romi, R. and Majori, G. (2008): An overview of the lesson learned in almost 20 years of fight against the 'tiger' mosquito. Parassitologia 50, 117-119.

Stefkov, S. and Gjorgov, A. (1967): A case of subcutaneous nodular dirofilariasis in the Macedonian Socialist Republic. Liječ. Vjesn. 89, 641-646.

Svobodova, Z., Svobodova, V., Genchi, C. and Forejtek, P. (2006): The first report of autochthonous dirofilariosis in dog in the Czech Republic. Helminthologia 43, 242-245.

Tasić, A., Rossi, L., Tasić, S., Miladinović-Tasić, N., Ilić, T. and Dimitrijević, S. (2008): Survey of canine dirofilariasis in Vojvodina, Serbia. Parasitol. Res. 103, 1297-1302.

Tasić, S., Stailjković, N., Miladinović-Tasić, N., Tasić, A., Mihailović, D., Rossi, L., Gabrielli, S. and Cancrini, G. (2011): Subcutaneous dirofilariosis in South-East Serbia - Case report. Zoonoses Public Health 58, 318-322.

Tasić, A., Tasić-Otašević, S., Gabrielli, S., Miladinović-Tasić, N., Ignjatović, A., Djordjević, J., Dimitrijević, S. and Cancrini, G. (2012): Canine Dirofilaria infections in two uninvestigated areas of Serbia: epidemiological and genetic aspects. Vector-Borne Zoonot. 12, 1031-1035.

Tasić-Otašević, S. A., Gabrielli, S. V., Tasić, A. V., Kostić, J. T., Ignjatović, A. M., PopovićDragonjić, L. D., Milošević, Z. G., Arsić-Arsenijević, V. S. and Cancrini, G. A. (2014): Seroreactivity to Dirofilaria antigens in people from different areas of Serbia. BMC Infect. Dis. 14, 68 .

Valerio, L., Marini, F., Bongiorno, G., Fahinelli, L., Pombi, M., Caputo, B., Maroli, M. and della Torre, A. (2008): Blood-feeding preferences of Aedes albopictus (Diptera: Culicidae) in urban and rural settings within the Province of Rome, Italy. Parassitologia 50, 103-104.

Webber, W. A. F. and Hawking, F. (1955): Experimental maintenance of Dirofilaria repens and Dirofilaria immitis in dogs. Exp. Parasitol. 4, 143-164. 